\title{
Pensononowoor
}

2016, vol. 76, 35-49

http://dx.doi.org/10.12657/denbio.076.004

\author{
Xiao Guo, Ren-Qing Wang, Cheng-Dong Wang, Fei Xu, Song Zhao, \\ Wei-Hua Guo*
}

\section{Acer truncatum seedlings are more plastic than Quercus variabilis seedlings in response to different light regimes}

Received: 5 January 2016; Accepted: 18 May 2016

\begin{abstract}
In this study, we investigated responses of the mid-successional species Acer truncatum Bunge and the late-successional species Quercus variabilis Blume to three solar illumination conditions: (1) constant low light (CL), (2) constant high light (CH) and (3) low light first and high light afterwards (LH). The last treatment was to simulate a canopy opening. Both species exhibited increases in biomass, totally and in part, and decreases in leaf water content, specific leaf area and chlorophyll concentrations in LH treatment compared to CL treatment. For A. truncatum, exposure to high light condition (LH) increased crown area, and decreased root to shoot ratio, stem mass ratio and leaf perimeter. However, for Q. variabilis, LH treatment increased stem diameter at ground height, effective quantum yield, photochemical quenching and decreased maximum photosystem II quantum yield. The biomass allocation pattern did not change in $Q$. variabilis among three light conditions. With respect to newly developed leaves, no significant differences were found in leaf size of $Q$. variabilis between $\mathrm{LH}$ treatment and $\mathrm{CH}$ treatment while that of $A$. truncatum decreased in LH treatment. All chlorophyll fluorescence parameters in newly developed oak leaves in LH treatment increased compared to those of $\mathrm{CH}$ treatment while no difference was found for A. truncatum between $\mathrm{LH}$ and $\mathrm{CH}$ treatment. A. truncatum displayed a greater overall plasticity than $\mathrm{Q}$. variabilis although the oak seedlings have a greater plasticity with respect to chlorophyll concentration and chlorophyll fluorescence parameters. A. truncatum should be a better candidate for vegetation recovery, especially in places with heterogeneous light conditions.
\end{abstract}

Keywords: irradiance acclimation, chlorophyll fluorescence, morphology, photoinhibition

\footnotetext{
Addresses: X. Guo, College of Landscape Architecture and Forestry, Qingdao Agricultural University, Qingdao 266109, P.R. China

X Guo, R-Q Wang, C-D Wang, S Zhao, W-H Guo, Institute of Ecology and Biodiversity, School of Life Sciences, Shandong University, Jinan, 250100, P.R. China; Shandong Provincial Engineering and Technology Research Center for Vegetation Ecology, Shandong University, Jinan, 250100, P.R. China, e-mail: guo_wh@yahoo.com

F Xu, College of Life Sciences, Shandong Normal University, Jinan, 250014, P.R. China

${ }^{*}$ Corresponding author
} 


\section{Introduction}

Tree seedlings regenerating in the understory experience much spatial and temporal heterogeneity of light conditions (Wyka et al., 2008). Increased light exposure, which may occur as the result of canopy gap formation produced by windfalls and similar events, accelerates the development of regenerating young plants (Naramoto et al., 2006). When excess light cannot be utilized, however, photoinhibition- which means the slow reversible decline of photosynthetic efficiency (Demmig-Adams \& Adams, 1992; Kitao et al., 2000)- may occur, constraining seedling growth. Acclimation of shade plants to gap opening is critical, as it affects growth rates and eventually determines plant survival and fitness (Azevedo \& Marenco, 2012). Tree seedlings that can minimize photoinhibition and acclimate rapidly to changes in light intensity may gain a substantial advantage in growth and regeneration (Kitao et al., 2000).

A number of investigations have been conducted to examine plant morphological and physiological responses to variations in illumination (Gatti et al., 2011; Guo et al., 2013; Naramoto et al., 2006; Saldaňa-Acosta et al., 2009; Tobita et al., 2010; Valladares et al., 2002; Yamashita et al., 2000). In some of these studies, plants were subjected to low light illumination for some time and then were transferred to high light condition. However, these studies focused on the effects of high light exposure on existing leaves rather than on the leaves produced in response to high light conditions. The new leaves sprouted after high light exposure, however, are important in determining the future of seedlings.

One investigation carried out in subtropical islands of Japan did focus on the new leaves sprouted after high light exposure (Yamashita et al., 2000). In that study, however, the leaves developed after high light exposure were compared to leaves that had developed in low light or high light before high light exposure and grown continuously in low light or high light, respectively. As leaf age may have a significant effect on photosynthetic properties (Bertamini \& Nedunchezhian, 2002) and on the ability to acclimate to shifts in light intensity (Wyka et al., 2008), it would be more meaningful to compare the influence of light on leaves after high light exposure using leaves all at the same stages of development. Further information concerning such newly developed leaves, which is crucial to regeneration of understory vegetation under gap conditions, is therefore needed.

Acer truncatum Bunge (Shantung maple) and Quercus variabilis Blume (Chinese cork oak) are two common deciduous species that are distributed widely in China and are also found in Japan and Korea. Both species play crucial roles in forest ecosystems and are used as important potential candidate species for revegetation in temperate area. A. truncatum has medical and ornamental uses. Q. variabilis is a valuable timber tree commonly used as industrial raw materials and also used for tannin extract. A. truncatum can be seen frequently in forests, parks, both sides of roads and family courtyards. Q. variabilis, however, are mainly distributed in natural areas. A. truncatum is a mid-successional species (Wang, 2005), while $Q$. variabilis is late-successional (Wu et al., 2001; Yang et al., 2010). However, in despite of different successional status, the two species often co-occur in warm temperate forest.

Many studies have been carried out using a variety of species to examine the relationship between shade tolerance, successional stage, and acclimation to sudden increases in light (Azevedo \& Marenco, 2012; Kitao et al., 2000; Naramoto et al., 2006; Valladares et al., 2002). Generally, early successional species exhibit higher plasticity than late successional shade-tolerant species (Azevedo \& Marenco, 2012; Naramoto et al., 2006). For example, Minquartia quianensis, a late successional species, experienced severe photoinhibition and loss of leaves during transition to full-sun conditions due to lack of physiological plasticity, compared to Swietenia macrophylla, a middle successional species.

However, to the best of our knowledge, these two important tree species have not been compared with respect to the responses to various light conditions and sudden increase of light intensity. Given the above background, we implemented a study to simulate gap conditions by transferring potted seedlings from low light environments to high light environments, and recorded morphological and physiological acclimation of leaves as well as entire seedlings. Both the leaves developed before and after transfer were measured. Our goals were to compare the responses of two species to varied light conditions and to a sudden increase in light intensity and provide suggestions for using two species for vegetation restoration.

\section{Methods}

\section{Study site and plant materials}

The research was carried out at the Fanggan Research Station of Shangdong University, Laiwu, Shandong Province, China $\left(36^{\circ} 26^{\prime} \mathrm{N}, 117^{\circ} 27^{\prime} \mathrm{E}\right)$. This study site has a warm temperate monsoon climate, with an average temperature of $13 \pm 1^{\circ} \mathrm{C}$, and an average annual precipitation of $700 \pm 100 \mathrm{~mm}$, most of which falls during the summer (Zhang et al., 2006). To avoid natural precipitation and ensure a controlled and homogenous environment, the entire experiment was conducted in the research station 
greenhouse $(20.0 \times 9.0 \times 5.0 \mathrm{~m}$, length $\times$ width $\times$ height). Ventilation was controlled by raising and lowering the plastic side films. The plastic side films were raised in daytime to 2.0 meters high and lowered to 0.5 meters high at night.

Seeds of both species were purchased from Dacheng Seed Company (Jinan, China). The seeds used in present study were harvested in early winter of 2010. These seeds were air-dried and stored at $0-4{ }^{\circ} \mathrm{C}$ throughout the winter until the next May. In May of year 2011, A. truncatum seeds and Q. variabilis acorns were soaked in water for $24 \mathrm{~h}$ and preserved in wet gauze at $0-4{ }^{\circ} \mathrm{C}$ to stimulate germination. For use as a substrate, silt soil and humic soil were collected near the station, air-dried, and mixed in a 2:1 (v/v) ratio. Healthy and uniform germinated seeds were selected and sown in these pots. The germinated seedlings were transferred into 9-L plastic pots $(32 \mathrm{~cm}$ high $\times 29 \mathrm{~cm}$ diameter, one seedling per pot) containing $6.0 \mathrm{~kg}$ of the silt soil /humic soil mixture. Prior to the beginning of the experiment, all pots were irrigated regularly and subjected to manual weed control.

\section{Experimental design}

All light treatments were carried out in shade shelters covered by either plastic film or woven black nylon nets. The mean photosynthetic photon flux density in the shelters covered by plastic film was $80 \%$ of that outside the greenhouse, and was designed to represent forest gap light conditions. The mean photosynthetic photon flux density under the black nylon nets was $8 \%$ of that outside the greenhouse, simulating understory illumination. The black nylon nets $(5.0 \times 2.5 \times 3.0 \mathrm{~m}$, length $\times$ width $\times$ height $)$ were built in the middle of the greenhouse. The photon flux density (PFD) of the outside, inside of the greenhouse and of the black nylon nets were 1055.2 $\pm 101.9, \quad 844.0 \pm 81.8$ and $85.0 \pm 8.0 \mathrm{umol}$ $\mathrm{m}^{-2} \mathrm{~s}^{-1}$ (average value from 7 a.m. to 7 p.m.; $\mathrm{n}=24$; data recorded twice every hour). The temperatures within the greenhouse and the black nylon nets were $27.46 \pm 0.25$ and $27.14 \pm 0.21^{\circ} \mathrm{C}$ (average value from 25 July to 25 August, 2011; $\mathrm{n}=752$; data recorded every hour; recorded by MicroLog EC650, Fourtec, USA) respectively, and no significant difference was found $(p=0.325)$.

Seedlings were raised in both light environments in the first place. There were seven seedlings of each species in the light condition of $80 \%$ of full sun and fourteen plants of each species in the light condition of $8 \%$ of full sun, thus forty two seedlings were used for both species. After about two months of treatment, half of the understory seedlings (seven plants) were transferred to the gap condition, i.e. the light condition of $80 \%$ of full sun. The remaining seedlings were kept in their original environments, whether understory (low light) or gap (high light). Seedlings were therefore subjected to one of three different treatments: continuous low light (CL), continuous high light $(\mathrm{CH})$, or transfer from low to high light conditions (LH). There were seven replicates for each treatment.

All plants were watered when necessary to eliminate the influence of drought during the experiment. The experiment was conducted over the entire growing season, from 5 Jun-9 Sep 2011. The transfer began at 1 Aug 2011.

\section{Measurements}

The leaves were measured for leaf traits, chlorophyll fluorescence parameters and pigment concentration. The measurements of these leaves were carried out at the end of the experiment. Two fully developed leaves (third to fifth leaves from the tip) of each replication were labeled in different colors before transfer. The leaves labeled in the first color were used to measure the chlorophyll fluorescence parameters and pigment concentration. The leaves labeled in the other color were used to measure leaf traits. The newly developed leaves were measured for leaf traits and chlorophyll fluorescence parameters and no label was attached to these leaves.

Only fully expanded leaves were selected, for both the leaves developed before transfer and the leaves developed after transfer. Although every seedling developed new leaves after transfer, we were limited to four replications per treatment in the case of $Q$. variabilis because there were not as many fully developed ones as the maple seedlings (which were seven replications per treatment). In CL environment, there were less than four replications developed new fully expanded leaves after transfer for both species. Therefore the comparison of new developed leaves was limited between $\mathrm{CH}$ and $\mathrm{LH}$ treatments.

Ten soil samples were collected before the experiment started to represent the soil background and were analyzed at Shandong Agricultural University. Organic matter concentration was analyzed using potassium dichromate-volumetric method. Available soil nitrogen and available soil phosphorus were analyzed using the alkali-diffusion method and Olsen method, respectively. Total soil nitrogen and total soil phosphorus were analyzed using Kjeldahl method and fused sodium hydroxide Mo-Sb colorimetry method, respectively. The $\mathrm{pH}$ values were measured using a pH-meter (PHSJ-3F, Shanghai Precision Scientific Instrument Co., Ltd, Shanghai, China). 


\section{Leaf traits}

Before transferring, seven leaves of each treatment were labeled to measure leaf parameters as below. Leaf features of seven (for A. truncatum) or four (for Q. variabilis) newly developed leaves per treatment were also recorded as below.

Leaf morphology was measured in late August. Leaves were scanned with an Epson Perfection V700 scanner (Seiko Epson, Nagano, Japan). Mean leaf area and mean leaf perimeter were calculated from the scanned images using an Image-Pro Plus Version 4.5 image analyzer (Media Cybernetic, Silver Spring, MD, USA). To calculate leaf water content and specific leaf area, leaves were weighed before and after drying in an oven at $80^{\circ} \mathrm{C}$ for $48 \mathrm{~h}$. Leaf water content was calculated as: (leaf fresh mass - leaf dry mass) / leaf fresh mass (Guo et al., 2013).

\section{Chlorophyll fluorescence parameters}

Chlorophyll fluorescence parameters were obtained using a Mini-PAM pulse amplitude modulation chlorophyll fluorometer (Walz GmbH, Effeltrich, Germany). To ensure complete relaxation of all reaction centers, leaves were kept in the dark for at least 30 min prior to taking measurements. Maximum photosystem II (PSII) quantum yield $\left(\mathrm{F}_{\mathrm{v}} / \mathrm{F}_{\mathrm{m}}\right)$ was calculated as:

$$
\mathrm{F}_{\mathrm{v}} / \mathrm{F}_{\mathrm{m}}=\left(\mathrm{F}_{\mathrm{m}}-\mathrm{F}_{0}\right) / \mathrm{F}_{\mathrm{m}}
$$

where $\mathrm{F}_{0}$ is the minimum chlorophyll fluorescence, determined using a measuring beam, and $\mathrm{F}_{\mathrm{m}}$ is the maximum chlorophyll fluorescence, recorded after $0.8 \mathrm{~s}$ saturating pulse light ( $\left.c a .8,000 \mu \mathrm{mol} \mathrm{m} \mathrm{m}^{-2} \mathrm{~s}^{-1}\right)$.

Maximum fluorescence in the light-saturated stage $\left(\mathrm{F}_{\mathrm{m}}^{\prime}\right)$ and fluorescence yield in the steady state $\left(\mathrm{F}_{\mathrm{s}}\right)$ were determined after the application of actinic light (ca. $402 \mu \mathrm{mol} \mathrm{m} \mathrm{m}^{-2} \mathrm{~s}^{-1}$ ) for $50 \mathrm{~s}$ to drive photosynthesis. Effective quantum yield (yield) was calculated according to Geel et al. (1997) and Genty et al. (1989). Photochemical quenching (qP) and non-photochemical quenching (qN) were calculated according to Schreiber et al. (1986).

Chlorophyll fluorescence parameters were recorded the day before transfer and monitored eight times (day2, day4, day5, day9, day11, day15, day20, day31) afterwards over the course of 31 days, with four replicates per treatment of each species. These dates were selected because they are the only sunny days thereafter.

Chlorophyll fluorescence parameters of new developed leaves were also measured at day 31, with four replicates per treatment of each species. All chlorophyll fluorescence parameters were recorded between 8:00 AM and 10:00AM.

\section{Leaf pigments}

These four fully expanded leaves of each treatment which were used for measurements of chlorophyll fluorescence parameters were also selected for chlorophyll concentration measurements. Chlorophyll a and chlorophyll b were extracted and measured 31 days after transfer according to the method of $\mathrm{Li}$ chtenthaler and Wellburn (1983) using a UV-2100 spectrophotometer (Unico, ShangHai, China). Chlorophyll a and chlorophyll b concentrations were calculated per unit dry mass for four replicates of each treatment.

\section{Biomass and biomass allocation}

At the end of the experiment, the shoot height, stem diameter at ground height (about $1 \mathrm{~cm}$ above the ground line, DGH), and crown area of each seedling was recorded. Crown area of each seedling was calculated as: crown area $=0.5 \mathrm{ab}$ ( $\mathrm{a}$ and $\mathrm{b}$ were the length of diagonal when look directly down the plant) (Guo et al., 2013). Then we got the average crown area from seven replicates of each treatment.

All seedlings were then harvested and divided into main root, lateral root, stems, and leaves (leaf blade and petiole for maple tree). The main root was defined as the root that developed directly from the seed, while the lateral roots were the roots that extended from the main root (Guo et al., 2013). Each portion was weighed after oven-drying at $80^{\circ} \mathrm{C}$ for $48 \mathrm{~h}$.

Total biomass, root mass ratios, stem mass ratios and leaf mass ratios were calculated as follows:

total biomass $=$ main root biomass + lateral root biomass + stem biomass + leaf biomass;

root mass ratio $=$ (main root biomass + lateral root biomass)/total biomass;

stem mass ratio $=$ stem biomass $/$ total biomass;

leaf mass ratio $=$ leaf biomass/total biomass.

\section{Statistical analysis}

Two-way analysis of variance (ANOVA) was used to compare the effects of species and light treatment. One-way ANOVA was performed to detect significant differences among the three treatments for every parameter within each species. All Two-way and one-way ANOVAs were accompanied by Duncan's multiple range tests, with a 0.05 significance level. Before carrying out the ANOVAs, data were checked for normality and homogeneity of variance, and were log-transformed when necessary. A T-test was conducted to detect differences between $\mathrm{CH}$ and $\mathrm{LH}$ treatments for 
newly developed leaves. ANOVAs and T-tests were performed using SPSS 13.0 (SPSS, Chicago, Illinois, USA). Figures were drawn using Origin 8.0 (OriginLab, Northhampton, Massachusetts, USA).

Comparing the differences of the ecological acclimation between two species seems to be complex as there are so many parameters to consider. Therefore, principal component analysis (PCA) account for most of the variability in the data was applied. A small number of linear combinations of parameters which vary significantly among different light conditions and species were obtained. The components with eigenvalues greater than one were extracted. The principal component analysis was conducted by JMP 10.0 (SAS Institute Inc., North Carolina, USA), using all the data measured. The first two components were selected to make the biplot.
The phenotypic plasticity indices (PIs) of each species were calculated according to Valladares et al. (2006) to compare the degree of plasticity among the clones as a response to different light treatments. The index was calculated for all the morphological and physiological parameters as: PI $=$ (maximum mean - minimum mean)/ maximum mean. Maximum mean and minimum mean stand for the maximum and minimum mean values for every parameter among all the treatments, respectively.

\section{Results}

The organic matter concentration, available soil nitrogen, available soil phosphorus, total soil nitrogen, total soil phosphorus and $\mathrm{pH}$ of the soil before

Table 1. Results of two-way analysis of variance (ANOVA) for both species on morphological and physiological parameters, with species and light treatment as fixed factors

\begin{tabular}{|c|c|c|c|}
\hline \multirow{2}{*}{ Parameter } & \multicolumn{3}{|c|}{ Source of variation } \\
\hline & Species (d.f. $=1$ ) & Light treatment (d.f.=2) & Species $*$ Light treatment \\
\hline \multicolumn{4}{|c|}{ Growth and biomass parameters } \\
\hline Height & 0.71 & $35.24^{* *}(\mathrm{CH})$ & $16.89^{* *}$ \\
\hline Crown & $10.11^{* *}<$ & $24.41^{* *}(\mathrm{CH})$ & $5.01^{*}$ \\
\hline Leaf biomass & 1.11 & $34.55^{* *}(\mathrm{CH})$ & $3.77^{*}$ \\
\hline Stem biomass & 0.26 & $26.36^{* *}(\mathrm{CH})$ & $3.33^{*}$ \\
\hline Main root biomass & $44.10^{* *}<$ & $55.62 * *(\mathrm{CH})$ & $8.05^{* *}$ \\
\hline Lateral root biomass & 1.04 & $13.40^{* *}(\mathrm{CH})$ & 2.10 \\
\hline Total biomass & 0.27 & $40.09 * *(\mathrm{CH})$ & 1.43 \\
\hline Root to shoot ratio & $13.54^{* *}<$ & $3.69 *(\mathrm{CL})$ & 2.23 \\
\hline Main to lateral root ratio & $7.86^{* *}<$ & 0.18 & 2.79 \\
\hline Root mass ratio & $25.07^{* *}<$ & $7.99 * *(\mathrm{CL})$ & $6.08^{* *}$ \\
\hline Stem mass ratio & 2.05 & $5.47^{* *}(\mathrm{CL}, \mathrm{CH})$ & $7.51^{* *}$ \\
\hline Leaf mass ratio & $19.73^{* *}>$ & $14.38^{* *}(\mathrm{CH}, \mathrm{LH})$ & $9.48^{* *}$ \\
\hline \multicolumn{4}{|c|}{ Leaf traits } \\
\hline LWC & $175.86^{* *}>$ & $61.67^{* *}(\mathrm{CL})$ & 2.44 \\
\hline Leaf area & 3.84 & $21.42^{* *}(\mathrm{CH})$ & $11.59^{* *}$ \\
\hline Leaf perimeter & 3.77 & $78.18^{* *}(\mathrm{CH})$ & $51.14^{* *}$ \\
\hline SLA & $163.26^{* *}>$ & $238.54^{* *}(\mathrm{CL})$ & $6.44^{* *}$ \\
\hline \multicolumn{4}{|c|}{ Chlorophyll content and fluorescence parameters } \\
\hline Chl a & 0.46 & $82.67^{* *}(\mathrm{CL})$ & $4.17^{*}$ \\
\hline Chl b & 0.004 & $97.45^{* *}(\mathrm{CL})$ & 2.89 \\
\hline $\mathrm{Chl} \mathrm{a+b}$ & 0.16 & $89.05^{* *}(\mathrm{CL})$ & $3.68^{*}$ \\
\hline Chla/b & $38.38^{* *}<$ & $112.20 * *(\mathrm{CH})$ & $8.59 * *$ \\
\hline $\mathrm{F}_{\mathrm{v}} / \mathrm{F}_{\mathrm{m}}$ & 0.74 & $12.46^{* *}(\mathrm{CL}, \mathrm{CH})$ & 1.48 \\
\hline Yield & $12.11^{* *}>$ & $40.11^{* *}(\mathrm{CH})$ & $6.13^{* *}$ \\
\hline Etr & $12.11^{* *}>$ & $40.11^{* *}(\mathrm{CH})$ & $6.13^{* *}$ \\
\hline qP & $23.80^{* *}>$ & $38.80^{* *}(\mathrm{CH})$ & $11.16^{* *}$ \\
\hline $\mathrm{qN}$ & $10.86^{* *}>$ & 0.93 & $7.24^{* *}$ \\
\hline
\end{tabular}

$\mathrm{N}=7$ for growth parameters, biomass parameters, leaf traits and fluorescence parameters within each treatment, $\mathrm{n}=4$ for chlorophyll content within each treatment.

$<$ the mean value of $A$. truncatum is higher than that of $Q$. variabilis.

$>$ the mean value of $A$. truncatum is lower than that of $Q$. variabilis.

The treatment(s) in brackets indicate(s) it has(they have) highest value(s) of the corresponding parameter(s).

LWC leaf water content; SLA specific leaf area; ML main root mass to lateral root mass; Chl a Chlorophyll a; Chl b Chlorophyll b; $\mathrm{F}_{v} / \mathrm{F}_{\mathrm{m}}$ maximum photosystem II (PSII) quantum yield; Yield effective quantum yield; qP photochemical quenching; qN non-photochemical quenching.

Significance level: ${ }^{* * *} p<0.001,{ }^{* *} p<0.01,{ }^{*} p<0.05$, ns $p>0.05$. 
the experiment were $13.7 \pm 0.21 \mathrm{~g} \mathrm{~kg}^{-1}, 59.46 \pm 1.08$ $\mathrm{mg} \mathrm{kg}-1,19.29 \pm 0.66 \mathrm{mg} \mathrm{kg}{ }^{-1}, 0.59 \pm 0.02 \mathrm{~g} \mathrm{~kg}^{-1}$, $0.90 \pm 0.02 \mathrm{~g} \mathrm{~kg}^{-1}$ and $6.62 \pm 0.04(\mathrm{n}=10$ for all parameters), respectively. Both species and light treatment have greatly affected the performance of the seedlings (Table 1). Significant interactions between species and light treatment were found for most parameters measured (Table 1).

\section{Growth and biomass parameters}

For most morphological parameters, including growth parameters and leaf traits, the $\mathrm{CH}$ treatment was the highest among the three light conditions (Table 1). The crown area, main root biomass, root to shoot ratio, main to lateral root ratio and root mass ratio of the oak tree were larger than those of the maple tree, while leaf mass ratio displayed the opposite, when the data of all three treatments were pooled together (Table 1). Height and crown area increased after exposure to high light for both species although significant differences were found only in the crown area of maple tree, compared to the CL treatment (Table 2). Stem diameter at ground height of oak tree increased significantly in LH treatment compared to CL treatment (Table 2). All growth traits displayed highest value in $\mathrm{CH}$ treatments for both species.

All seedlings of both species that had been subjected to the $\mathrm{CH}$ treatment displayed the largest biomass production, in every part of the plant (Fig. 1a, b). For most of these biomass production parameters displayed significant increases in LH treatments, compared to CL treatments (Fig. 1a, b). For the oak seedlings, lateral root biomass in LH condition was not significantly different from that of CL treatment.

All biomass allocation parameters of $A$. truncatum seedlings displayed significant differences among varied light conditions (Fig. 1c). Nevertheless, no
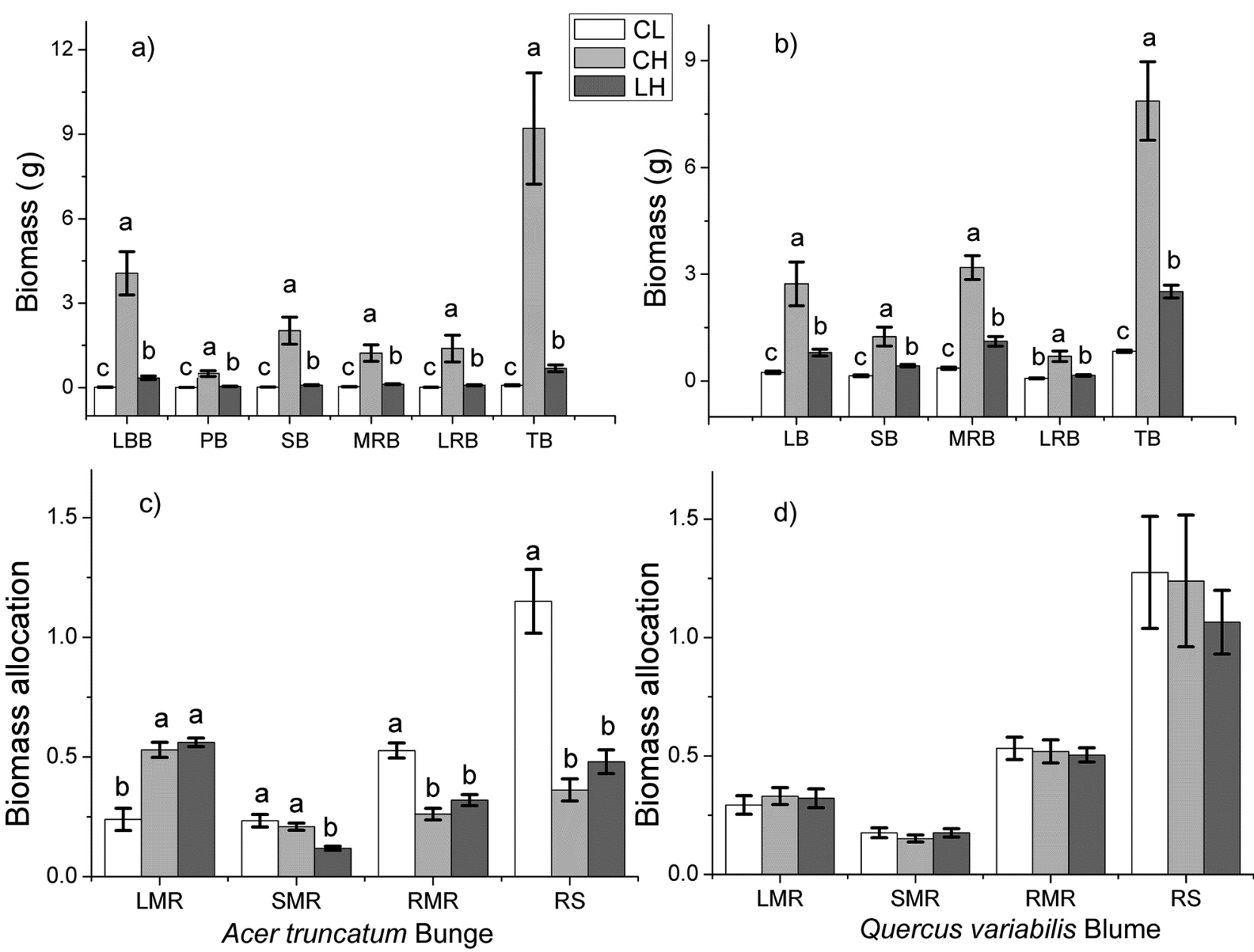

Fig. 1. Comparisons of biomass production and partitioning of A. truncatum and Q. variabilis seedlings under different light treatments. The data are means \pm SE $(n=7)$. Different letters indicate significant differences $(\mathrm{p} \leq 0.05)$ among different treatments according to Duncan's multiple range test.

LBB: leaf blade biomass; PB: petiole biomass; SB: stem biomass; MRB: main root biomass; LRB: lateral root biomass; TB: total biomass; LMR: leaf mass ratio; SMR: stem mass ratio; RMR: root mass ratio; RS: root to shoot ratio; CL: constant low light treatment; $\mathrm{CH}$ : constant high light treatment; LH: low light to high light treatment. 
Table 2. Growth traits of Acer truncatum Bunge and Quercus variabilis Blume at the end of the experiment under different light treatments

\begin{tabular}{ccccccccc}
\hline & \multicolumn{4}{c}{ Acer truncatum Bunge } & \multicolumn{4}{c}{ Quercus variabilis Blume } \\
\cline { 2 - 9 } & $\mathrm{CL}$ & $\mathrm{CH}$ & $\mathrm{LH}$ & $\mathrm{P}$ & $\mathrm{CL}$ & $\mathrm{CH}$ & $\mathrm{LH}$ & $\mathrm{P}$ \\
\hline Height $(\mathrm{mm})$ & $7.46 \pm 0.25 \mathrm{~b}$ & $52.43 \pm 6.1 \mathrm{a}$ & $11.04 \pm 1.7 \mathrm{~b}$ & $0.00^{* *}$ & $20.23 \pm 2.7$ & $31.37 \pm 3.9$ & $26.76 \pm 2.4$ & $0.06^{\text {ns }}$ \\
Crown $\left(\mathrm{mm}^{2}\right)$ & $18.30 \pm 4.3 \mathrm{c}$ & $363.3 \pm 42.8 \mathrm{a}$ & $103.0 \pm 21.1 \mathrm{~b}$ & $0.00^{* *}$ & $200.5 \pm 23.7$ & $329.9 \pm 46.1$ & $231.0 \pm 41.7$ & $0.07^{\text {ns }}$ \\
DGH $(\mathrm{mm})$ & & & & & $1.81 \pm 0.07 \mathrm{c}$ & $4.00 \pm 0.2 \mathrm{a}$ & $2.46 \pm 0.1 \mathrm{~b}$ & $0.00^{* *}$ \\
\hline
\end{tabular}

Each value is the mean \pm SE of 7 replicates. Significant differences between means of different treatments are marked with different letters.

Crown crown area; DGH stem diameter at ground height (about $10 \mathrm{~mm}$ above the ground line).

Significance level: ${ }^{* * *} p<0.001,{ }^{* *} p<0.01,{ }^{*} p<0.05$, ns $p>0.05$.

differences were found for any of these parameters of Q. variabilis (Fig. 1d). In maple seedlings, root mass ratio and root to shoot ratio were largest in the CL groups while no significant differences were found between $\mathrm{CH}$ and LH seedlings. High light exposure increased leaf mass ratio of $A$. truncatum seedlings compared with $\mathrm{CL}$ treatment. High light exposure significantly decreased the stem mass ratio in the maple seedlings, compared to the seedlings subjected always to low light or high light (Fig. 1c).

\section{Leaf traits}

Wilting of the leaves was observed for both species after transfer, with $A$. truncatum seedlings more apparent than $Q$. variabilis.

The leaf water content and specific leaf area of the maple tree were larger than those of the oak tree, when the data of all three treatments were pooled together (Table 1). The leaf water content and specific leaf area were larger in CL conditions than in other light treatments, while leaf area and leaf perimeter were largest in $\mathrm{CH}$ conditions, when the data of two species were pooled together (Table 1). As shown in Fig. 2, mean leaf area and perimeter were unchanged for $Q$. variabilis following all light treatments, while mean leaf area and perimeter of $A$. truncatum seedlings grown in $\mathrm{CH}$ condition were biggest among the three conditions. Transferring seedlings to high light condition (LH) did not affect the leaf size of the oak seedlings, but the leaf perimeter of the maple tree decreased significantly in LH treatment compared to CL treatment (Fig. 2c). Leaf water content and specific leaf area were reduced after exposure to high light for both species (Fig. 2a, d). Leaf water content and specific leaf area of the two species displayed highest values in CL treatments (Fig. 2a, d).

With respect to newly developed leaves in either species, transferred plants did not display any differences in water content and specific leaf area compared with ones continuously growing under high light conditions (Fig. 2e, h). In maple, newly developed leaves following transfer were remarkably smaller than their counterparts from $\mathrm{CH}$-treated seedlings (Fig. 2f, g). Mean leaf area and leaf perimeter of newly developed
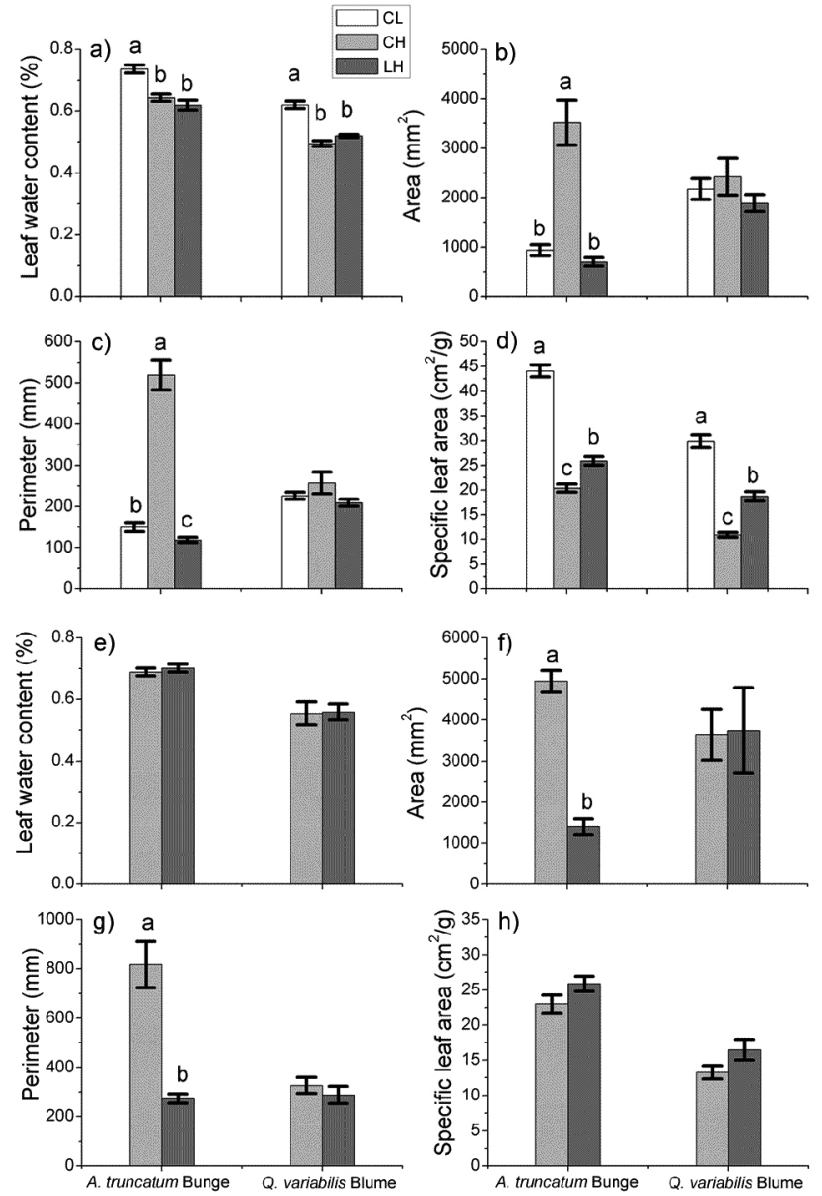

Fig. 2. Comparisons of leaf traits of $A$. truncatum and $Q$. variabilis seedlings under different light treatments. (a) Leaf water content, (b) mean leaf area, (c) leaf perimeter, and (d) specific leaf area were obtained from leaves that developed before transfer. (e) Leaf water content, (f) mean leaf area, (g) leaf perimeter, and (h) specific leaf area were measured from newly developed leaves that developed after transfer. The data are means \pm SE $(n=7$, except $n=4$ for newly developed leaves of $Q$. variabilis). Different letters indicate significant differences $(\mathrm{p} \leq 0.05)$ among different treatments according to Duncan's multiple range test.

CL: constant low light treatment; $\mathrm{CH}$ : constant high light treatment; LH: low light to high light treatment. 


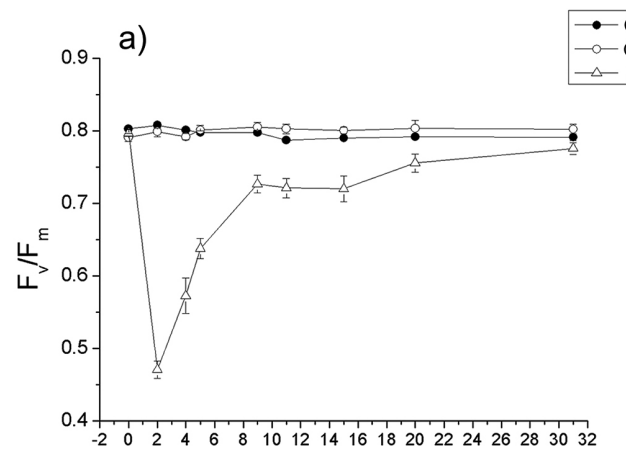

b)
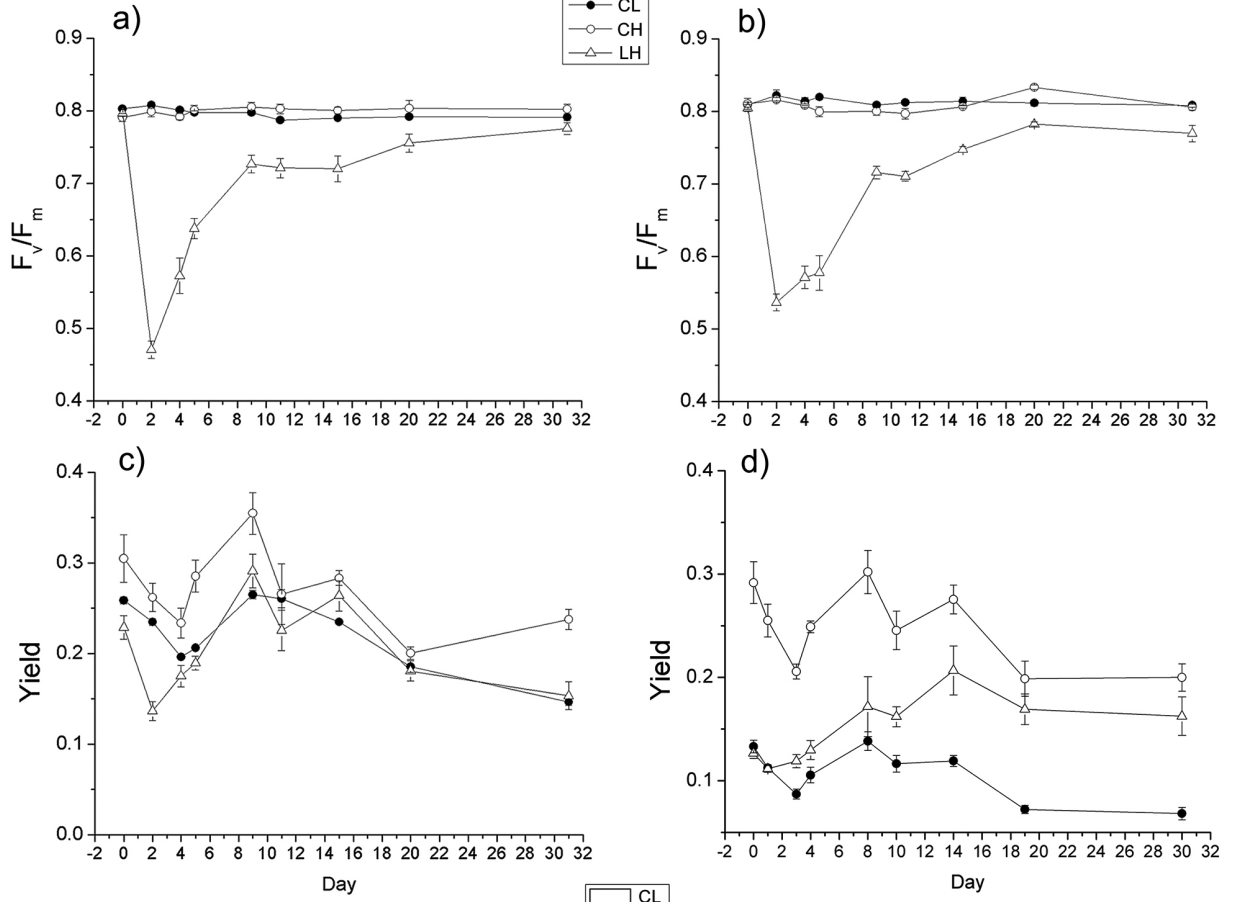

e)

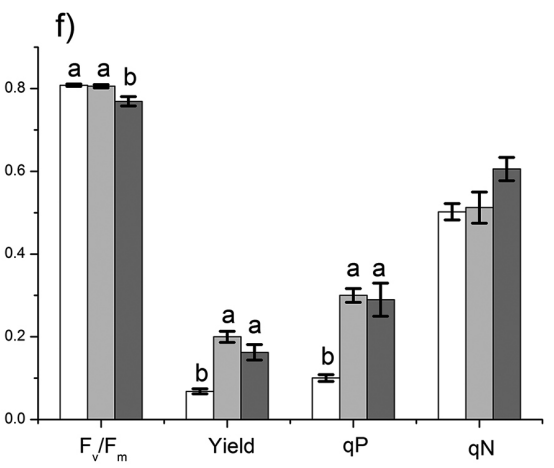

g)

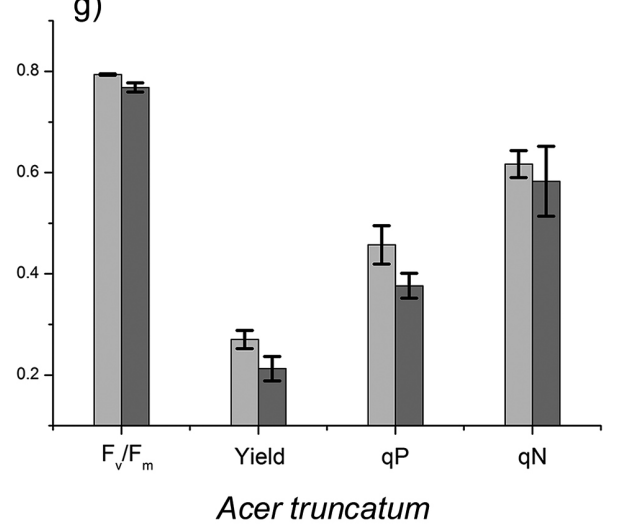

h)

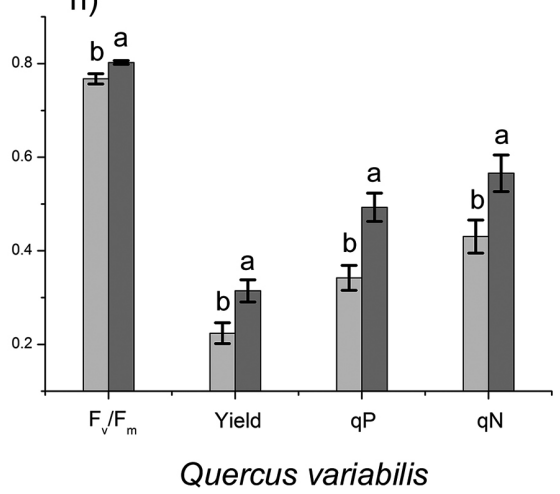

Fig. 3. Comparisons of chlorophyll fluorescence parameters before (day 0) and after (days 1-31) transfer of selected seedlings to high light conditions and the chlorophyll fluorescence parameters of newly developed leaves at the end of the experiment.

a: $F_{v} / F_{m}$ of the maple leaves developed before transfer during the 32 days; $b: F_{v} / F_{m}$ of the oak leaves developed before transfer during the 32 days; c: Yield of the maple leaves developed before transfer during the 32 days; d: Yield of the oak leaves developed before transfer during the 32 days after transfer; e: chlorophyll fluorescence parameters of the maple leaves at day 31 ; f: chlorophyll fluorescence parameters of the oak leaves at day 31; g: chlorophyll fluorescence parameters of the new leaves of the maple leaves at day 31 ; h: chlorophyll fluorescence parameters of the new leaves of the oak leaves at day 31 . The data are means \pm SE ( $\mathrm{n}=4$ ). Different letters indicate significant differences $(\mathrm{p} \leq 0.05)$ among different treatments according to Duncan's multiple range test.

$\mathrm{F}_{\mathrm{v}} / \mathrm{F}_{\mathrm{m}}$ : maximum photosystem II (PSII) quantum yield; Yield: effective quantum yield; qP: photochemical quenching; qN: non-photochemical quenching; $\mathrm{CL}$ : constant low light treatment; $\mathrm{CH}$ : constant high light treatment; LH: low light to high light treatment. 
oak leaves did not display any differences between $\mathrm{CH}$ treatment and $\mathrm{LH}$ treatment.

\section{Chlorophyll fluorescence}

Most fluorescence parameters except maximum photosystem II (PSII) quantum yield of the maple tree were larger than those of the oak tree, when the data of all three treatments were pooled together (Table 1). The CL treatment had largest chlorophyll content, while most fluorescence parameters except non-photochemical quenching were largest in $\mathrm{CH}$ treatment, when the data of two species were pooled together (Table 1).

In seedlings of both species subjected to LH treatment, $F_{v} / F_{m}$ experienced a sharp decrease initially and then gradually recovered (Fig. 3a, b). $\mathrm{F}_{\mathrm{v}} / \mathrm{F}_{\mathrm{m}}$ of $A$. truncatum in LH-treated seedlings reached the same level to that of $\mathrm{CL}$ and $\mathrm{CH}$ finally (Fig. 3e). However, at day $31, \mathrm{~F}_{\mathrm{v}} / \mathrm{F}_{\mathrm{m}}$ of the oak trees in $\mathrm{LH}$ condition was significantly lower than that of $\mathrm{CL}$ and $\mathrm{CH}$ conditions (Fig. 3f). Yield of LH-treated maple seedlings also displayed a considerable initial decrease and then mild recovery (Fig. 3c). For oak seedlings subjected to LH treatment, yield decreased slightly and then increased quickly over the following few days (Fig. 3d). At day 31, all chlorophyll fluorescence parameters except non-photochemical quenching of $Q$. variabilis displayed significant differences among varied light treatments (Fig. 3f). Transferred oak leaves have a significant higher yield and photochemical quenching than those of $\mathrm{CL}$ leaves while $\mathrm{F}_{\mathrm{v}} / \mathrm{F}_{\mathrm{m}}$ was restrained after transfer for 31 days. For $A$. truncatum seedlings, the differences of $\mathrm{F}_{\mathrm{v}} / \mathrm{F}_{\mathrm{m}}$ among varied light conditions were not significant (Fig. 3e). However, yield, photo- chemical quenching and non-photochemical quenching of transferred maple trees kept the same level with $\mathrm{CL}$ leaves, significantly lower than $\mathrm{CH}$ leaves.

With respect to newly developed leaves, $F_{v} / F_{m}$, yield, photochemical quenching and non-photochemical quenching of oak seedlings under LH treatment were significantly higher than under $\mathrm{CH}$ (Fig. 3h). In contrast, all chlorophyll fluorescence parameters of LH-treated A. truncatum were slightly lower than in seedlings subjected to $\mathrm{CH}$ treatment, but none of the differences is significant (Fig. 3g).

Both species in this study exhibited similar trends with respect to chlorophyll concentration and chlorophyll a to chlorophyll b ratios (Fig. 4). After transfer, both chlorophyll a and chlorophyll b concentrations of the two tree species decreased to the same levels found in $\mathrm{CH}$ leaves. Chlorophyll concentration of CL-treated leaves, including chlorophyll a, chlorophyll $\mathrm{b}$ and chlorophyll $\mathrm{a}+\mathrm{b}$, were highest among three light treatments. The ratio of chlorophyll a to chlorophyll b was significantly lower in plants grown under LH conditions compared with those subjected to the $\mathrm{CH}$ treatment, but noticeably greater than in CL-treated plants (Fig. 4a, b).

\section{Principal component analysis}

The principal component analysis extracted four components with eigenvalues greater than one, of all parameters among light treatments and species. The first two components accounted for $62.9 \%$ of the variability in the original data (Table 3, Fig. 5). The three treatments were separated clearly along the PC1 axis and the two species were separated clearly along PC2 axis. The first principal component (PC1
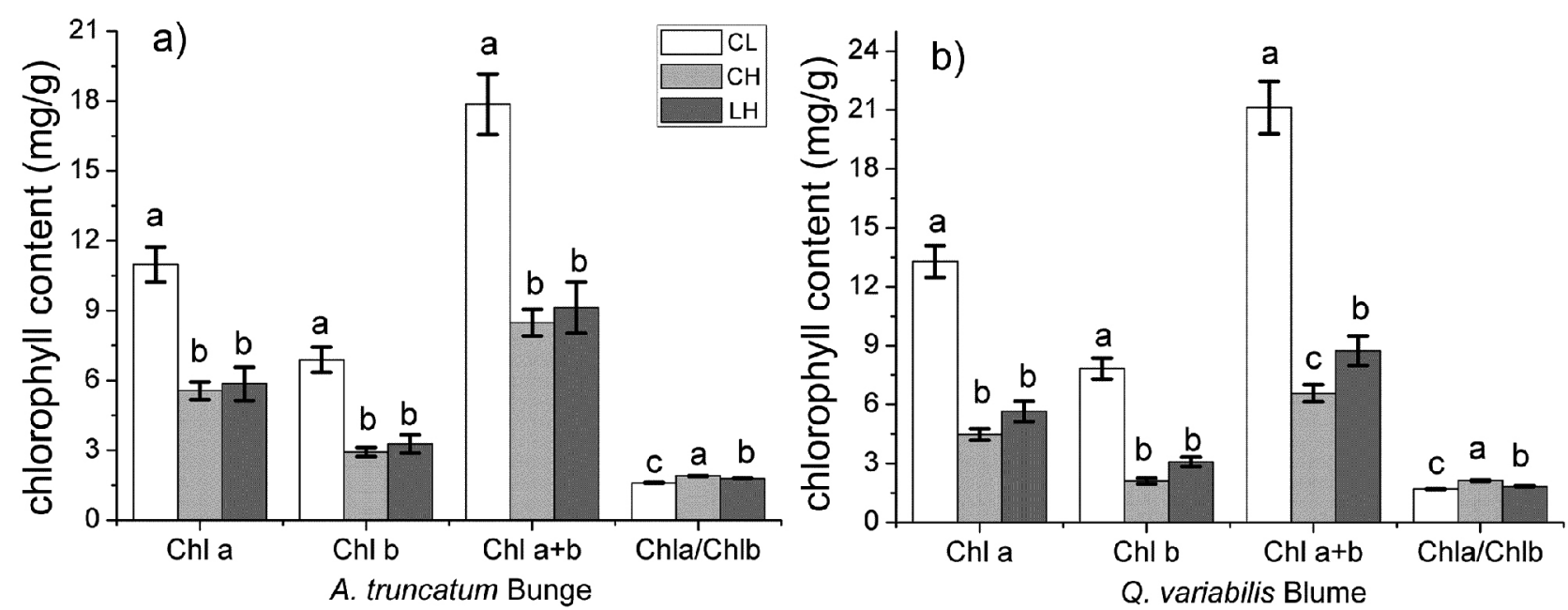

Fig. 4. Comparisons of chlorophyll content and chlorophyll a to chlorophyll b ratio of (a) A. truncatum and (b) Q. variabilis seedlings under different light treatments. Leaves were labeled before transfer and sampled 31 days after transfer. The chlorophyll content was expressed in dry mass. Data are means \pm SE $(n=4)$. Different letters indicate significant differences $(p \leq 0.05)$ among different treatments according to Duncan's multiple range test

Chl a: chlorophyll a; Chl b: chlorophyll b; CL: constant low light treatment; $\mathrm{CH}$ : constant high light treatment; LH: low light to high light treatment. 
Table 3. Principal component analysis of morphological and physiological parameters of the two deciduous tree species under three light conditions. $\left(\mathrm{N}_{\text {total }}=24\right)$

\begin{tabular}{|c|c|c|}
\hline & $\mathrm{PC} 1$ & PC2 \\
\hline Eigenvalue & 10.7110 & 3.7483 \\
\hline Proportion of variance $(\%)$ & 46.570 & 16.297 \\
\hline Cumulative proportion of variance (\%) & 46.570 & 62.867 \\
\hline \multicolumn{3}{|l|}{ Variable } \\
\hline \multicolumn{3}{|c|}{ Growth and biomass parameters } \\
\hline Height & 0.86111 & 0.11978 \\
\hline Crown area & 0.82331 & 0.33576 \\
\hline Stem biomass & 0.90252 & 0.14365 \\
\hline Main root biomass & 0.65718 & 0.63171 \\
\hline Lateral root biomass & 0.74624 & 0.10407 \\
\hline Total biomass & 0.91191 & 0.26292 \\
\hline Root to shoot ratio & -0.46333 & 0.76512 \\
\hline Main root to lateral root ratio & -0.45169 & 0.42216 \\
\hline Root mass ratio & -0.47620 & 0.78886 \\
\hline Stem mass ratio & 0.03454 & -0.12935 \\
\hline Leaf mass ratio & 0.42755 & -0.68109 \\
\hline \multicolumn{3}{|l|}{ Leaf traits } \\
\hline Leaf area & 0.71933 & 0.16541 \\
\hline Leaf perimeter & 0.82566 & -0.03215 \\
\hline SLA & -0.62767 & -0.48112 \\
\hline Leaf water content & -0.25546 & -0.65331 \\
\hline \multicolumn{3}{|c|}{ Chlorophyll concentration and fluorescence parameters } \\
\hline $\mathrm{F}_{\mathrm{v}} / \mathrm{F}_{\mathrm{m}}$ & 0.18593 & 0.39826 \\
\hline Yield & 0.83542 & -0.16446 \\
\hline Etr & 0.83542 & -0.16446 \\
\hline $\mathrm{qP}$ & 0.82592 & -0.30466 \\
\hline $\mathrm{qN}$ & 0.41054 & -0.50442 \\
\hline Chlorophyll a & -0.71197 & 0.02676 \\
\hline Chlorophyll b & -0.73309 & -0.01787 \\
\hline
\end{tabular}

Variables with high loadings (score $>0.8$ for PC1; score $>0.7$ for PC2) are shown in bold.

SLA specific leaf area; $\mathrm{F}_{\mathrm{v}} / \mathrm{F}_{\mathrm{m}}$ maximum photosystem II (PSII) quantum yield; Yield effective quantum yield; Etr electron transport rate; qP photochemical quenching; qN non-photochemical quenching.

axis) explained the largest percentage of the variation $(46.57 \%$, Table 3$)$. This component had high loadings for leaf perimeter, chlorophyll fluorescence parameters, height, crown area, leaf biomass, stem biomass and total biomass and was, therefore, interpreted as a 'factor of absorbing and utilizing sunlight'. The second principal component (PC1 axis) explained an additional $16.297 \%$ of the variation and had high loadings for root to shoot ratio and root mass ratio, thus this factor can be interpreted as a 'resource allocation factor' (Table 3). The distribution order of two tree species seedlings along PC1 axis is similar, mainly $\mathrm{LH}, \mathrm{CH}$ and $\mathrm{CL}$ seedlings from positive coordinate to negative coordinate (Fig. 5).

\section{Plasticity indices}

As shown in Table 4, the overall $\mathrm{PI}_{\text {diff }}$ is 4.32 , revealing the overall plasticity index of $A$. truncatum is

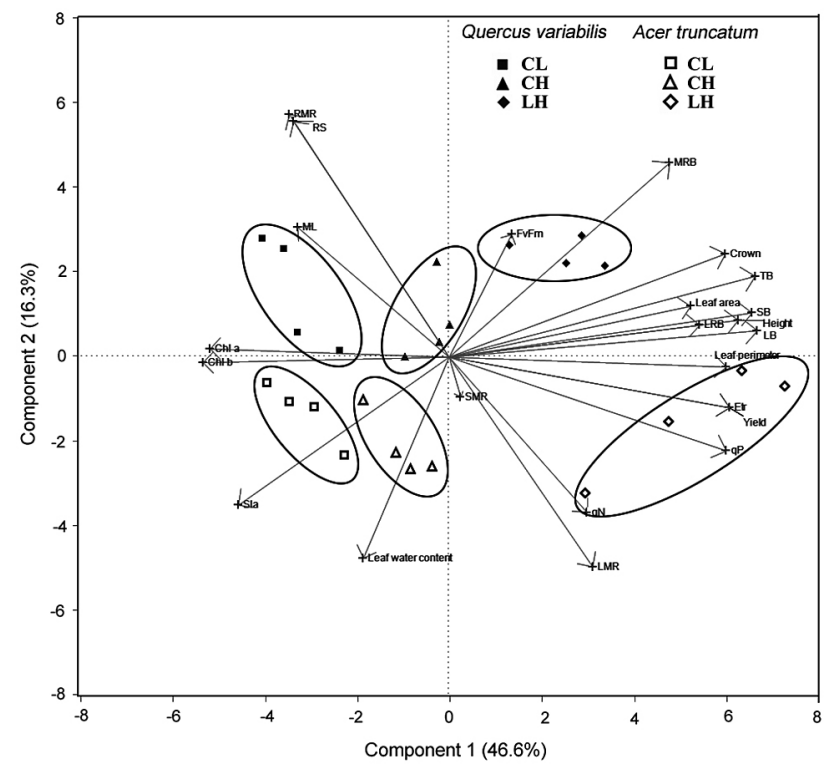

Fig. 5. Principal component biplots based on morphological and physiological indexes of the two tree species under three solar illumination conditions. Four samples of each treatment per species were collected. The parameters of newly developed leaves were not included because there were no leaves for LH seedlings

TB: total biomass; LB: leaf biomass; SB: stem biomass; MRB: main root biomass; LRB: lateral root biomass; LMR: leaf mass ratio; SMR: stem mass ratio; RMR: root mass ratio; ML: main root to lateral root ratio; $\mathrm{RS}$ : root to shoot ratio; $\mathrm{F}_{/} / \mathrm{F}_{\mathrm{m}}$ : maximum photosystem II (PSII) quantum yield; Yield: effective quantum yield; qP: photochemical quenching; qN: non-photochemical quenching; Chl a: chlorophyll a; Chl b: chlorophyll b; CL: constant low light treatment; $\mathrm{CH}$ : constant high light treatment; LH: low light to high light treatment.

much higher than Q. variabilis. A. truncatum has greater plasticity index with respect to growth parameters, leaf traits, biomass parameters and allocation parameters. Q. variabilis has greater plasticity index over the maple seedlings with respect to chlorophyll concentration and fluorescence parameters.

\section{Discussion}

Both species and light treatments affected the performance of the seedlings significantly. The significant interactions of species and light treatment for most parameters measured suggest the responses of two species to various light treatments may be quite different.

\section{Plant growth}

Upon exposure to strong illumination, transferred A. truncatum and Q. variabilis seedlings experienced increases in total biomass, and, for oak seedlings only, stem diameter at ground height, yield, photochemical quenching and non-photochemical quenching, compared to those parameters in CL seedlings. 
Table 4. Phenotypic plasticity of A. truncatum Bunge and Q. variabilis Blume under different light treatments

\begin{tabular}{|c|c|c|c|c|c|c|c|}
\hline \multirow{2}{*}{ Parameters } & \multicolumn{3}{|c|}{ A. truncatum Bunge } & \multicolumn{3}{|c|}{ Q. variabilis Blume } & \multirow{2}{*}{$\begin{array}{c}\mathrm{PI}_{\text {diff }} \\
\mathrm{PI}_{\mathrm{A}}-\mathrm{PI}_{O}\end{array}$} \\
\hline & Minimum & Maximum & Plasticity Index & Minimum & Maximum & Plasticity Index & \\
\hline \multicolumn{8}{|c|}{ Growth parameters } \\
\hline Height & 7.46 & 52.43 & 0.858 & 20.23 & 31.37 & 0.355 & 0.503 \\
\hline Crown & 18.3 & 363.3 & 0.950 & 200.5 & 329.9 & 0.392 & 0.557 \\
\hline \multicolumn{8}{|c|}{ Leaf traits } \\
\hline LWC & 0.62 & 0.74 & 0.162 & 0.49 & 0.62 & 0.210 & -0.048 \\
\hline Leaf area & 698.98 & 4941.72 & 0.858 & 1890.37 & 3742.74 & 0.495 & 0.364 \\
\hline Leaf perimeter & 118 & 817.05 & 0.856 & 209.08 & 326.03 & 0.359 & 0.497 \\
\hline Leaf length & 36.08 & 90.35 & 0.600 & 82.32 & 129.8 & 0.366 & 0.235 \\
\hline Leaf width & 28.41 & 132.05 & 0.785 & 32.09 & 44.36 & 0.277 & 0.508 \\
\hline SLA & 0.2 & 0.44 & 0.545 & 0.11 & 0.3 & 0.633 & -0.088 \\
\hline \multicolumn{8}{|c|}{ Biomass and allocation parameters } \\
\hline Leaf biomass & 0.02 & 4.57 & 0.996 & 0.8 & 2.73 & 0.707 & 0.289 \\
\hline Stem biomass & 0.02 & 2.03 & 0.990 & 0.15 & 1.25 & 0.880 & 0.110 \\
\hline Main root biomass & 0.03 & 1.23 & 0.976 & 0.36 & 3.19 & 0.887 & 0.088 \\
\hline Lateral root biomass & 0.01 & 1.39 & 0.993 & 0.08 & 0.7 & 0.886 & 0.107 \\
\hline Total biomass & 0.08 & 9.21 & 0.991 & 0.84 & 7.87 & 0.893 & 0.098 \\
\hline Root to shoot ratio & 0.36 & 1.15 & 0.687 & 1.06 & 1.27 & 0.165 & 0.521 \\
\hline ML & 1.3 & 5.67 & 0.771 & 4.94 & 7.48 & 0.340 & 0.431 \\
\hline Root mass ratio & 0.26 & 0.53 & 0.509 & 0.5 & 0.53 & 0.057 & 0.453 \\
\hline Stem mass ratio & 0.12 & 0.23 & 0.478 & 0.15 & 0.18 & 0.167 & 0.312 \\
\hline Leaf mass ratio & 0.24 & 0.56 & 0.571 & 0.29 & 0.33 & 0.121 & 0.450 \\
\hline \multicolumn{8}{|c|}{ Chlorophyll concentration and fluorescence parameters } \\
\hline Chl a & 5.56 & 10.98 & 0.494 & 4.47 & 13.28 & 0.663 & -0.170 \\
\hline Chl b & 2.93 & 6.88 & 0.574 & 6.57 & 21.12 & 0.688 & -0.115 \\
\hline $\mathrm{Chl} \mathrm{a/} \mathrm{Chl} \mathrm{b}$ & 1.6 & 1.9 & 0.158 & 1.7 & 2.14 & 0.206 & -0.048 \\
\hline $\mathrm{F}_{\mathrm{v}} / \mathrm{F}_{\mathrm{m}}$ & 0.47 & 0.81 & 0.420 & 0.54 & 0.82 & 0.341 & 0.078 \\
\hline Yield & 0.14 & 0.35 & 0.600 & 0.07 & 0.29 & 0.759 & -0.159 \\
\hline Etr & 23 & 59.85 & 0.615 & 11.52 & 51 & 0.774 & -0.159 \\
\hline qP & 0.25 & 0.68 & 0.632 & 0.1 & 0.72 & 0.861 & -0.229 \\
\hline $\mathrm{qN}$ & 0.5 & 0.81 & 0.383 & 0.29 & 0.84 & 0.655 & -0.272 \\
\hline Total & & & 17.452 & & & 13.137 & 4.32 \\
\hline
\end{tabular}

$\mathrm{N}=7$ for growth parameters and biomass parameters within each treatment, $\mathrm{n}=4$ for chlorophyll content within each treatment, $\mathrm{n}=7$ for leaf traits and fluorescence parameters of $A$. truncatum and old $Q$. variabilis leaves within each treatment; $\mathrm{n}=4$ for leaf traits and fluorescence parameters of new $Q$. variabilis leaves within each treatment.

$\mathrm{PI}_{\text {Diff }}$ the differences between plasticity index of A. truncatum $\left(\mathrm{PI}_{\mathrm{A}}\right)$ and plasticity index of Q. variabilis $\left(\mathrm{PI}_{\mathrm{Q}}\right)$; Crown crown area; LWC leaf water content; SLA specific leaf area; ML main root mass to lateral root mass; chl a Chlorophyll a; chl b Chlorophyll b; $F_{v} / F_{m}$ maximum photosystem II (PSII) quantum yield; Yield effective quantum yield; qP photochemical quenching; qN non-photochemical quenching.

These results suggest that the introduction of intense light had a positive effect on both tree seedlings.

Change of root to shoot ratio might reflect an acclimation to differences in available light: if light is the major limiting resource, a high resource allocation to shoots would be a successful acclimation to out-compete neighboring plants (Hees \& Clerkx, 2003). This strategy was adopted by several species (Gatti et al., 2011; Saldaňa-Acosta et al., 2009; Valladares et al., 2002). The present results obtained from the middle successional A. truncatum do not appear to support this hypothesis: the root to shoot ratio was higher in CL-treated plants than in those subjected to $\mathrm{CH}$ or $\mathrm{LH}$ treatments, suggesting that under low light conditions, A. truncatum seedlings allocate more resources to the roots. A. truncatum seedlings thus adopted an opposite strategy, investing carbon in the roots in shade, which may aid survival during unfavorable periods, assist in recovery from herbivore damage (Lusk, 2002). This conclusion could be inferred from the lower leaf mass ratio and higher root mass ratio of $A$. truncatum seedlings in shade as well (Fig. 1c). No difference of any biomass allocation parameters was observed under various light conditions for $Q$. variabilis, indicating the oak trees did not adopt either strategy.

In A. truncatum seedlings, mean leaf area and perimeter of leaves developed before exposure were largest in $\mathrm{CH}$ treatment (Fig. 2b, c), whereas those parameters of $Q$. variabilis were unaffected by light availability (Fig. 2b, c). Furthermore, perimeter of shade-developed maple leaves decreased when they were exposed to high light conditions (Fig. 2c). The decreases might be explained by the increase in 
thickness of shade-developed leaves following transfer as indicated by decreased specific leaf area (Fig. $2 \mathrm{~d}$ ). These results suggest the oak is less plastic than the maple seedlings.

In addition to the root to shoot ratio, specific leaf area - the light-capturing area per unit of previously captured mass-is another important variable used to describe shade tolerance (Saldaňa-Acosta et al., 2009). In present study, the highest specific leaf areas of both species were detected under low light conditions (Fig. 2d), which consists with many previous studies (Gatti et al., 2011; Naramoto et al., 2006; Valladares et al., 2002; Yamashita et al., 2000). A high specific leaf area under shady conditions allows seedlings to capture light resources with less investment per area unit to the leaves, thus increasing shade tolerance.

With respect to newly developed $\mathrm{LH}$ leaves of $Q$. variabilis, we found that none of the measured leaf traits differed significantly from those $\mathrm{CH}$-treated leaves (Fig. 2e, f, g, h). This result indicates that the newly developed oak leaves cannot adjust themselves to acclimate to the new environment and are simply not phenotypically plastic with regards to leaf size (mean leaf area and perimeter) and thickness. In contrast, newly developed LH leaves of A. truncatum were significantly smaller in size than those of their $\mathrm{CH}$ counterparts (Fig. 2f, g), indicating that this species made certain adjustment and had a greater phenotypic plasticity.

In maples, but not oaks, shoot height, crown area, all biomass allocation parameters, mean leaf area (for both leaves developed before and after transfer), leaf perimeter (for both leaves developed before and after transfer) were significantly affected by different irradiance treatments. All these provide support for the viewpoint that $A$. truncatum seedlings has greater plasticity in response to different light conditions than Q. variabilis, with respect to whole plant growth morphology and traits of leaves developed before and after transfer. This conclusion was strengthened by the plasticity indices in Table 4 .

\section{Chlorophyll fluorescence}

$\mathrm{F}_{\mathrm{v}} / \mathrm{F}_{\mathrm{m}}$, yield, photochemical quenching, non-photochemical quenching reflect the maximal and effective quantum yield of PSII (Colom et al., 2003), the proportion of PSII reaction centers that are open (Dai et al., 2009; Maxwell \& Johnson, 2000), and the degree of plants harmlessly-dissipated excess excitation energy that has already been absorbed as heat (Muller et al., 2001), respectively. $\mathrm{F}_{\mathrm{v}} / \mathrm{F}_{\mathrm{m}}$, the primary target of photoinhibitory processes (Hussner et al., 2010), has been shown to be a reliable indicator of PSII activity (Demmig \& Bjorkman, 1987; Dias \& Marenco, 2006; Hussner et al., 2010; Tobita et al.,
2010). As in previous studies (Dias \& Marenco, 2006; Kitao et al., 2000; Naramoto et al., 2006; Tobita et al., 2010; Valladares et al., 2002; Yamashita et al., 2000), we found that when shade-developed leaves were exposed to high light, $\mathrm{F}_{\mathrm{v}} / \mathrm{F}_{\mathrm{m}}$ decreased at the first measurement and subsequently recovered gradually, indicating photoinhibition and recovery of photoinhibition. The decline of $\mathrm{F}_{v} / \mathrm{F}_{\mathrm{m}}$ can happen after a very short time of exposure (Dias \& Marenco, 2006). Thirty one days after exposure, $\mathrm{F}_{\mathrm{v}} / \mathrm{F}_{\mathrm{m}}$ in shade-developed $A$. truncatum leaves had recovered to pre-exposure level, whereas $\mathrm{F}_{\mathrm{v}} / \mathrm{F}_{\mathrm{m}}$ of $Q$. variabilis had not. This result is consistent with previous conclusions in that the recovery of photoinhibition is related to the successional status of the species (Azevedo \& Marenco, 2012; Yamashita et al., 2000), in which $\mathrm{F}_{\mathrm{v}} / \mathrm{F}_{\mathrm{m}}$ recovered relatively quickly in mid-successional species than in late-successional ones. However, both $\mathrm{F}_{\mathrm{v}} / \mathrm{F}_{\mathrm{m}}$ of the two species reached similar values close to 0.8 , which is considered the reference value for health leaves (Bjorkman \& Demmig, 1987).

Yield of shade-developed maple leaves did not change after 31 days of acclimation to strong light exposure (Fig. 3c, e) while that of Q. variabilis increased significantly (Fig. 3d, f), indicating more efficient PSII of Q. variabilis after exposure. Decreasing in photochemical quenching is another indicator of chronic photoinhibition (Kitao et al., 2006). After 31 days of acclimation, A. truncatum kept pre-exposure level in respect to photochemical quenching, while $Q$. variabilis seedlings increased (Fig. 3e, f). This indicates that the oak possesses a greater ability of using high light than the maple leaves but neither of two species was inhibited by strong light exposure in terms of photochemical quenching.

Non-radiative energy dissipation of excess light energy can contribute to avoid chronic photoinhibition and prevent photoinhibitory damage (Iio et al., 2004). Contrary to previous studies (lio et al., 2004; Valladares et al., 2002), non-photochemical quenching of A. truncatum shade-developed leaves decreased under LH condition (Fig. 3e). However, that of $Q$. variabilis under $\mathrm{LH}$ condition did not display significant difference from CL and $\mathrm{CH}$ conditions (Fig. 3f). $Q$. variabilis therefore has a greater ability than $A$. truncatum in dissipation of excess light energy. This greater ability, together with larger photochemical quenching, may result in higher effective quantum yield of PSII of transferred Q. variabilis leaves.

For all chlorophyll fluorescence parameters in newly developed leaves of $A$. truncatum, no significant difference was found between $\mathrm{LH}$ condition and $\mathrm{CH}$ condition (Fig. 3g). However, newly developed LH leaves of Q. variabilis displayed a good performance to the bright light, with all the chlorophyll fluorescence parameters significantly higher than counterparts of $\mathrm{CH}$ treatment (Fig. 3h). These results, together with 
the results of the leaves developed before transfer, indicate that $Q$. variabilis has a greater plasticity and better acclimation capacity to sudden bright light exposure than $A$. truncatum in aspect of physiological performances. Plasticity indices data also strengthened this observation (Table 4).

As seen in previous research (Yamashita et al., 2000), the highest chlorophyll concentrations were seen in CL plants, with chlorophyll concentration in LH conditions decreased after transfer (Fig. 4). Under high light intensity conditions, low chlorophyll concentration can help plants to avoid excessive absorption of light energy (Kitao et al., 2000). Although PSII activity $\left(\mathrm{F}_{v} / \mathrm{F}_{\mathrm{m}}\right)$ of LH maple leaves returned to pre-exposure levels, the mass-based chlorophyll concentration did not restore in either species. This supports the viewpoint that PSII recovery processes are independent of chlorophyll concentration (Yamashita et al., 2000). For both species, the chlorophyll a to chlorophyll $\mathrm{b}$ ratios were highest in $\mathrm{CH}$ conditions and lowest in CL conditions, which is in accordance with previous results (Dai et al., 2009; Lei \& Lechowicz, 1998; Yamashita et al., 2000). On the contrary, Wyka et al. (2008) found that chlorophyll a to chlorophyll $b$ ratio was not affected by irradiance. The variation of the chlorophyll a to chlorophyll $b$ ratios among three light treatments in present study associated a greater investment in chlorophyll $b$ to enhance photosystem II function under low irradiance (Lei et al., 1996) and is an avoidance mechanism to reduce excess light absorption (Ishida et al., 2000), suggesting that the two species adopted smiliar strategies to cope with varied light conditions with respect to the chlorophyll content.

\section{Overall comparison}

In present study, plants were grown under the same conditions of soil, nutrient and water. Therefore, differences in responses to three light treatments for the same species should be concluded to phenotypic plasticity. Differences in morphological and physiological responses of two species in the same light treatment are concluded to genetic variation. Also the different phenotypic plasticity performances are also caused by genetic variation.

Generally, according to the biplot (Fig. 5), the two tree seedlings of LH treatments were much close to the seedlings of $\mathrm{CH}$ than to $\mathrm{CL}$ seedlings. This suggests that the current high light condition have a greater effect in the two tree seedlings than previous low light condition. Furthermore, the distribution pattern of the two species along PC1 axis is similar, indicating that the acclimation mechanisms in light absorbing and utilizing to different light conditions are to some extent similar. However, the range of $A$. truncatum along light absorbing and utilizing compo- nent (PC1) is much wider than that of $Q$. variabilis, providing support to the greater phenotypic plasticity of $A$. truncatum with respect to light absorbing and utilizing. The lower plasticity of the oak may due to the fact that late successional species is adapted to a generally less dynamic environment. The ranges of two species along PC2 are almost the same, indicating the similar phenotypic plasticity with respect to biomass allocation. With regards to the biomass allocation component (PC2), the two tree species is different in every light condition, indicating the genetically determined differences. The range of two tree seedlings along $\mathrm{PC} 1$ is much wider than that of PC2. Hence, the genetically determined differences between two species could be smaller than phenotypic plasticity within each species.

When first exposed to excess light, both A. truncatum and $Q$. variabilis seedlings were inhibited, but in the long term they were benefited from strong illumination. The responses observed in our study indicate the two tree species generally employed somewhat similar strategies to cope with varied light conditions in respect to absorbing and utilizing sunlight, but quite different strategies in respect to resource allocation. Seedlings of the mid-successional species $A$. truncatum exhibited greater plasticity than those of the late-successional species Q. variabilis. This was true both at the leaf level-for leaves developed before and after transfer-and at the whole plant level. Regulation of canopy density, e.g. release cutting and thinning, and control of competitors, especially tall rapidly-growing weeds that create shade, can enhance seedling growth and promote regeneration of both species. Furthermore, either forest management plan or silvicultural practices should not be established without considering successional status and phenotypic plasticity. As A. truncatum seedling generally displayed greater phenotypic plasticity, the maple tree should be a better candidate for vegetation, especially in the areas with heterogeneous light environment or natural and human disturbances. Since present study mainly focused on light intensity, more work is needed to clarify the effects of light quality on both species, although it has been reported that that forest maple seedlings responses mainly to light intensity rather than spectral quality (Lei \& Lechowicz, 1998).

\section{Acknowledgements}

We express our deep appreciation to Yifu Yuan and Ning Du for their assistance during experiment. This research was supported by the National Science Foundation of China (Nos. 31470402; 31270374) and the Science and Technology Project of Shandong Province (No. 2014GZX217005). 


\section{References}

Azevedo GFC \& Marenco RA (2012) Growth and physiological changes in saplings of Minquartia guianensis and Swietenia macrophylla during acclimation to full sunlight. Photosynthetica 50: 8694.

Bertamini M \& Nedunchezhian N (2002) Leaf age effects on chlorophyll, Rubisco, photosynthetic electron transport activities and thylakoid membrane protein in field grown grapevine leaves. Journal of Plant Physiology 159: 799-803.

Bjorkman O \& Demmig B (1987) Photon yield of $\mathrm{O}_{2}$ evolution and chlorophyll fluorescence characteristics and $77 \mathrm{~K}$ among vascular plants of diverse origin. Planta 170: 489-504.

Colom MR, Prato EP \& Giannini R (2003) Chlorophyll fluorescence and photosynthetic response to light in 1-year-old needles during spring and early summer in Pinus leucodermis. Trees 17: 207-210.

Dai Y, Shen Z, Liu Y, Wang L, Hannaway D \& Lu H (2009) Effects of shade treatments on the photosynthetic capacity, chlorophyll fluorescence, and chlorophyll content of Tetrastigma hemsleyanum Diels et Gilg. Environmental and Experimental Botany 65: 177-182.

Demmig-Adams B \& Adams WW III (1992) Photoprotection and other responses of plants to high light stress. Annual Review of Plant Physiology and Plant Molecular Biology 43: 599-626.

Demmig B \& Bjorkman O (1987) Comparison of the effect of excessive light on chlorophyll fluorescence $(77 \mathrm{~K})$ and photon yield of $\mathrm{O}_{2}$ evolution in leaves of higher plants. Planta 171: 171-184.

Dias DP \& Marenco RA (2006) Photoinhibition of photosynthesis in Minquartia guianensis and Swietenia macrophylla inferred by monitoring the initial fluorescence. Photosynthetica 44: 235-240.

Geel C, Versluis W \& Snel JFH (1997) Estimation of oxygen evolution by marine phytoplankton from measurement of the efficiency of photosystem II electron flow. Photosynthesis Research 51: 61-70.

Gatti MG, Campanello PI \& Goldstein G (2011) Growth and leaf production in the tropical palm Euterpe edulis: Light conditions versus developmental constraints. Flora 206: 742-748.

Genty B, Briantais JM \& Baker NR (1989) The relationship between the quantum yield of photosynthetic electron transport and quenching of chlorophyll fluorescence. Biochimica et Biophysica Acta 990: 87-92.

Guo X, Guo W, Luo Y, Tan X, Du N \& Wang R (2013) Morphological and biomass characteristic acclimation of trident maple (Acer buergerianum Miq.) in response to light and water stress. Acta Physiologiae Plantarum 35: 1149-1159.
Hees AFM \& Clerkx APPM (2003) Shading and rootshoot relations in saplings of silver birch, pedunculate oak and beech. Forest Ecology and Management 176: 439-448.

Hussner A, Hoelken HP \& Jahns P (2010) Low light acclimated submerged freshwater plants show a pronounced sensitivity to increasing irradiances. Aquatic Botany 93: 17-24.

Iio A, Fukasawa H, Nose Y \& Kakubari Y (2004) Stomatal closure induced by high vapor pressure deficit limited midday photosynthesis at the canopy top of Fagus crenata Blume on Naeba mountain in Japan. Trees 18: 510-517.

Ishida A, Toma T, Marjenah M (2000) Leaf gas exchange and canopy structure in wet and drought years in Macaranga conifera, a tropical pioneer tree: Rainforest Ecosystems of East Kalimantan. Springer Japan, pp. 129-142.

Kitao M, Lei TT, Koike T, Tobita H \& Maruyama Y (2000) Susceptibility to photoinhibition of three deciduous broadleaf tree species with different successional traits raised under various light regimes. Plant, Cell \& Environment 23: 81-89.

Kitao M, Yoneda R, Tobita H, Matsumoto Y, Maruyama Y, Arifin A, Azani AM \& Muhamad MN (2006) Susceptibility to photoinhibition in seedlings of six tropical fruit tree species native to Malaysia following transplantation to a degraded land. Trees 20: 601-610.

Lei TT \& Lechowicz MJ (1998) Diverse responses of maple saplings to forest light regimes. Annals of Botany 82: 9-19

Lei TT, Tabuchi R, Kitao M \& Koike T. (1996) Functional relationship between chlorophyll content and leaf reflectance, and light-capturing efficiency of Japanese forest species. Physiologia Plantarum 96: 411-418.

Lichtenthaler HK \& Wellburn AR (1983) Determinations of total carotenoids and chlorophylls a and b of leaf extracts in different solvents. Biochemical Society Transactions 11: 591-592.

Lusk CH (2002) Leaf area accumulation helps juvenile evergreen trees tolerate shade in a temperate rainforest. Oecologia 132: 188-196.

Maxwell K \& Johnson GN (2000) Chlorophyll fluorescence - a practical guide. Journal of Experimental Botany 51: 659-668.

Muller P, Li XP \& Niyogi KK (2001) Non-photochemical quenching. A response to excess light energy. Plant Physiology 125: 1558-1566.

Naramoto M, Katahata SI, Mukai Y \& Kakubari Y (2006) Photosynthetic acclimation and photoinhibition on exposure to high light in shade-developed leaves of Fagus crenata seedlings. Flora 201: 120-126.

Saldaňa-Acosta A, Meave JA \& Sánchez-Velásquez LR (2009) Seedling biomass allocation and vital rates 
of cloud forest tree species : Responses to light in shade house conditions. Forest Ecology and Management 258: 1650-1659.

Schreiber U, Schliwa U \& Bilger W (1986) Continuous recording of photochemical and non-photochemical chlorophyll fluorescence quenching with a new type of modulation fluorometer. Photosynthesis Research 10: 51-62.

Tobita H, Utsugi H, Kitao M, Kayama M, Uemura A, Kitaoka S \& Maruyama Y (2010) Variation in photoinhibition among Sasa senanensis, Quercus mongolica, and Acer mono in the understory of a deciduous broad-leaved forest exposed to canopy gaps caused by typhoons. Trees 24: 307-319.

Valladares F, Chico J, Aranda I, Balaguer L, Dizengremel P, Manrique E \& Dreyer E (2002) The greater seedling high-light tolerance of Quercus robur over Fagus sylvatica is linked to a greater physiological plasticity. Trees 16: 395-403.

Valladares F, Sanchez-Gomez D \& Zavala MA (2006) Quantitative estimation of phenotypic plasticity: bridging the gap between the evolutionary concept and its ecological applications. Journal of Ecology 94: 1103-1116.

Wang SS (2005) Study on forest health based on forest vegetation succession in mountain area of northern China. Forestry University of Beijing, Beijing.

Wu MZ, Liu YC \& Jiang ZL (2001) The reproductive ecology and stable mechanism of Quercus variabilis (Fagaceae) population. Acta Ecologica Sinica 21: 225-230.

Wyka T, Robakowski P \& Zytkowiak R (2008) Leaf age as a factor in anatomical and physiological acclimative responses of Taxus baccata L. needles to contrasting irradiance environments. Photosynthesis Research 95: 87-99.

Yamashita N, Ishida A, Kushima H \& Tanaka N (2000) Acclimation to sudden increase in light favoring an invasive over native trees in subtropical islands, Japan. Oecologia 125: 412-419.

Yang BL, Zhang WH \& Zhou JY (2010) Function of vegetative propagation on population regeneration of Quercus variabilis in different habitats on northern slope of Qinling Mountains. Journal of Northeast Forestry University 38: 27-29.

Zhang XQ, Liu J, Welham CVJ, Liu CC, Li DN, Chen L \& Wang RQ (2006) The effects of clonal integration on morphological plasticity and placement of daughter ramets in black locust (Robinia pseudoacacia). Flora 201: 547-554. 